\title{
Knowledge and Skills for Management of Sexually Transmitted Infections by Rural Medical Practitioners in Bangladesh
}

\author{
Nazmul Alam ${ }^{*}$, Malay K. Mridha², Sibylle Kristensen ${ }^{3}$, Sten H. Vermund ${ }^{4}$ \\ ${ }^{1}$ Research Centre of the University of Montreal Hospital (CRCHUM), Montreal, Canada \\ ${ }^{2}$ International Centre for Diarrhoeal Disease Research, Dhaka, Bangladesh \\ ${ }^{3}$ One Heart World-Wide, San Francisco, USA \\ ${ }^{4}$ Institute for Global Health, Vanderbilt University, Tennessee, USA \\ Email: ${ }^{*}$ nazmul.alam@umontreal.ca
}

Received 5 March 2015; accepted 4 April 2015; published 8 April 2015

Copyright (C) 2015 by authors and Scientific Research Publishing Inc.

This work is licensed under the Creative Commons Attribution International License (CC BY). http://creativecommons.org/licenses/by/4.0/

(c) (7) Open Access

\section{Abstract}

Sexually transmitted infection (STI) management is considered rudimentary among rural medical practitioners (RMPs) in Bangladesh. We sought to understand the level of knowledge and skills in STI management and to assess the impact of a two-day training orientation among RMPs in Tangail district. Data were collected through a baseline survey of 225 practicing RMPs in the study area and a three-month follow-up survey of 99 RMPs who participated in a two-day STI/HIV orientation training. The level of formal training among RMPs ranged from none $(22.7 \%)$, to paramedical training $(14.7 \%)$ and local medical assistant training $(62.6 \%)$. The baseline survey revealed a low level of STI/HIV knowledge and misconceptions about the transmission of STI/HIV among RMPs. RMPs mostly prescribed first line antibiotics for treatment of common reproductive tract infections (RTIs) including STIs, but they rarely prescribed the correct dosages according to the national RTI/STI management guidelines. Only 3\% of RMPs were able to correctly answer all four HIV transmission (unprotected sexual intercourse, blood transfusion, needle sharing and mother to child transmission) questions at baseline, while $94.9 \%$ of RMPs answered all four correctly at three months following the training $(p=0.001)$. Only $10 \%$ of RMPs reported suggesting the recommended drug (azithromycin) and only $2 \%$ mentioned about the recommended dosage ( 2 gm single dose) for the treatment of urethritis/cervicitis; compared to $49.5 \%$ suggested azithromycin at follow-up with $39.4 \%$ mentioned the recommended $2 \mathrm{gm}$ single dose $(p=0.001)$. Our study found low level of knowledge and poor practices related RTI/STI management among RMPs. Short orientation training and education intervention shown promise to increase knowledge and management skills for RTIs/STIs.

\footnotetext{
${ }^{*}$ Corresponding author.
}

How to cite this paper: Alam, N., et al. (2015) Knowledge and Skills for Management of Sexually Transmitted Infections by Rural Medical Practitioners in Bangladesh. Open Journal of Preventive Medicine, 5, 151-158. 


\title{
Keywords
}

\author{
Rural Medical Practitioners, STI Management, Bangladesh, HIV Knowledge, Informal Health \\ Providers
}

\section{Introduction}

Bangladesh is considered a low HIV prevalence country, it is vulnerable to epidemic because of its close proximity to Asian HIV epicentres and the presence of several high risk subgroups in the country [1]-[6]. The prevalence rates of curable sexually transmitted infections (STIs) among sex workers and other high risk groups in Bangladesh are high and consistent condom use in commercial sex is low [7] [8]. Effective STI management approaches along with other HIV/AIDS prevention efforts could play an important role in averting HIV/AIDS epidemic in Bangladesh. Because of the synergy and interrelationship in mode of transmission of STIs with HIV/AIDS, STI management is considered one of the proven tools in reducing HIV transmission in a population with a nascent epidemic [9]-[13].

Over $70 \%$ of Bangladesh's total population resides in rural areas with little access to formal health care. Only 2.5 qualified physicians are available per 10,000 populations, one of the lowest coverage rates in Asia [14]. The overwhelming majority of the rural population in Bangladesh seek medical care from rural medical practitioners (RMPs) also called "palli chikishok" or "grammo dakter", who use modern medicine but most of these practitioners were informally trained or self-trained without any formal medical education [15] [16]. Though RMPs are often the only medical care providers for most of Bangladesh's rural poor, there are no formal efforts to train them in disease management, including STIs, nor are there government regulations to monitor the quality of their practices [2]. RMPs are often not familiar with proper dosages of various medications and their potential side effects. One study indicated that RTIs were not well understood among village practitioners; they did not perform examination of their patients, used substandard dosage of drugs, and made no attempt to notify or treat sexual partners [17].

We conducted this study to assess level of knowledge and skills of RMPs in STI management, as well as to understand the impact of STI/HIV orientation training on several outcomes: RMPs abilities to comprehend STI syndromic guidelines and HIV transmission routes, to deliver better quality services, and to refer patients to certified physicians when appropriate.

\section{Materials and Methods}

The study was conducted between July 2002 and June 2003 in the Sadar than a (sub-district) of the Tangail district of Bangladesh among rural medical practitioners identified through a census in the study area. RMP spractice allopathic medicine for patient management, but they are not qualified medical graduates. Homeopaths and those who practice traditional or herbal medicines were not included in the study.

A baseline survey was conducted to collect information on socio-economic status, STI/HIV/AIDS related knowledge and skills, and STI patient care practices among the RMPs. Trained interviewers conducted personal interviews either at the RMPs' homes or their practices in the village markets, using a pre-tested structured questionnaire. An informed consent was obtained from each participating RMP. The protocol was reviewed and approved by the Institutional Review Board at the University of Alabama at Birmingham and locally by the Bangladesh Women's Health Coalition. A subgroup of the RMPs was invited to participate in a two-day STI/ HIV/ AIDS training session. Participants were selected using a priority scale based on: 1) higher average number of patients encounter per day; 2) higher average number of STI patients encounters in last month of interview; and 3) a longer duration of practice as a RMP. To allow for more interactive sessions, the RMPs were divided into four groups of 33 trainees. Trainers included medical doctors and public health experts with years of experience in clinical management of STIs and public health research. The training curriculum included brief discussion human reproductive systems, STI/HIV/AIDS, etiology and symptoms of common of STIs, overview of STI syndromic management approaches, importance of patient referral and other prevention approaches. Each participant received printed materials on STI/HIV/AIDS, national STI syndromic management guidelines, a list of possible referral sites for STI patients, and a book of 100 referral forms. A simple referral form was developed 
with two parts to record information on patient's name, age, key symptoms, and address of where being referred. Patients took one part with them to the providers being referred to, and RMP kept another part for their record. Three months following the training sessions, participating RMPs were re-interviewed with the same questionnaires as that used during the baseline survey. The follow-up survey was conducted to estimate the impact of training, focusing on knowledge and practices that RMPs could implement in their daily practice in STI management that was sustained three months following the training.

Data analysis: The data analysis was performed using SPSS $^{\circledR} 17$ version [18]. Chi-square and Fisher's exact test were used to compare categorical variables, and the non-parametric median test was used to compare continuous variables. Wilcoxon's matched pair test and McNemar's Chi-square test were performed when compared pre- and post-training status of selected variables on knowledge and practice. All $p$-values quoted are two sided, with a $p$-value $<0.05$ considered as significant.

\section{Results}

A total of 225 RMPs participated in the baseline survey, $91.8 \%$ of the 245 of those originally identified in the census, rest 20 RMPs either refused to participate or could not be reached for baseline survey with several attempts. A majority of the practicing RMPs were married (90.7\%) and men (98.7\%). Most (83.6\%) were Muslim, $16.4 \%$ were Hindu and nearly half (44.9\%) were between the age of 30 - 44 years (Table 1 ).

Formal training and STD knowledge: Among the RMPs, only $45.3 \%$ had a secondary or higher level of education, however, all of them were literate. The level of training prior practicing allopathic medicine ranged from no training reported by $22.7 \%$ of the RMPs, paramedical training reported by $14.7 \%$ (three years paramedical training mainly provided in government institutes), and local medical assistant (LMA) training (four to six months training mainly offered by the private institutions) reported by $62.6 \%$ of the RMPs. Only $15.5 \%$ of the

Table 1. Socio demographic characteristics of rural medical practitioners by level of knowledge.

\begin{tabular}{|c|c|c|c|}
\hline Characteristics N (\%) & $\begin{array}{c}\text { Baseline knowledge of } \leq 2 \\
\text { STI }(\mathrm{n}=190)\end{array}$ & $\begin{array}{c}\text { Baseline knowledge of }>2 \\
\text { STI }(\mathrm{n}=35)\end{array}$ & $\begin{array}{l}\text { Total number } \\
\quad(\mathrm{n}=225)\end{array}$ \\
\hline \multicolumn{4}{|l|}{ Sex } \\
\hline Male & 189 (99.5) & 33 (94.3) & 222 (98.7) \\
\hline Female & $1(0.5)$ & $2(5.7)$ & $3(1.3)$ \\
\hline \multicolumn{4}{|l|}{ Age $^{*}$} \\
\hline$\leq 29$ years & $49(25.8)$ & $16(45.7)$ & 65 (28.9) \\
\hline $30-44$ years & $87(45.8)$ & $14(40.0)$ & $101(44.9)$ \\
\hline$\geq 45$ & $54(28.4)$ & $5(14.3)$ & $59(26.2)$ \\
\hline \multicolumn{4}{|l|}{ Marital status } \\
\hline Unmarried & 15 (7.9) & $6(17.1)$ & $21(9.3)$ \\
\hline Married & $175(92.1)$ & $29(82.9)$ & $204(90.7)$ \\
\hline \multicolumn{4}{|l|}{ Religion } \\
\hline Muslim & $159(83.7)$ & 29 (82.9) & $188(83.6)$ \\
\hline Hindu & $31(16.3)$ & $6(17.1)$ & 37 (16.4) \\
\hline \multicolumn{4}{|l|}{ Education } \\
\hline Illiterate & - & - & 0 \\
\hline Up to secondary level & 87 (45.7) & 15 (42.9) & $102(44.9)$ \\
\hline Higher secondary & $66(34.8)$ & $16(45.7)$ & $82(36.4)$ \\
\hline > Higher secondary level & 37 (19.5) & $4(11.4)$ & $41(18.2)$ \\
\hline \multicolumn{4}{|l|}{ Training* } \\
\hline No formal training & $48(25.3)$ & $3(8.6)$ & $51(22.7)$ \\
\hline Paramedical & 25 (13.1) & $8(22.9)$ & 33 (14.7) \\
\hline Local medical assistant & $117(61.6)$ & $24(68.5)$ & $141(62.6)$ \\
\hline \multicolumn{4}{|l|}{ Times as a practitioner } \\
\hline$\leq 3$ years & $56(29.5)$ & 15 (42.9) & $71(31.6)$ \\
\hline $3-10$ years & $68(35.8)$ & $10(28.6)$ & $78(34.7)$ \\
\hline >10 years & $66(34.7)$ & $10(28.6)$ & $76(33.8)$ \\
\hline
\end{tabular}

\footnotetext{
*Significant difference among groups (Pearson Chi 6.53, p $<0.03$ and Fisher's Chi 6.10, p < 0.04 respectively).
} 
RMPs were able to correctly name three out of four common STDs (syphilis, gonorrhea, trichomoniasis, and HIV/AIDS) and their symptoms; none were able to identify all four. There was significantly higher knowledge of STIs among those who had paramedical training and were $<30$ years old compared to those who had no such training and were $\geq 30$ years old.

STD treatment practices: Most of the practitioners diagnose STIs through taking history of symptoms and/or exposure to high risk behaviours (65.4\% for male patients and $84.0 \%$ for female patients), while a few use laboratory investigations (35.6\% for male patients and $16 \%$ for female patients) (Table 2). The participated RMPs commonly sell medications to their patients (90.7\%) without written prescription (80.0\%). A significantly higher proportion of RMPS with paramedical training depended on laboratory investigations for STI diagnosis and they were more likely to give prescriptions to their patients and less likely to sell medications as compared to their non-paramedical counterparts.

More than half (51.5\%) of the RMPs reported that they prescribed ciprofloxacin for the treatment of gonorrhea, but among them, only 3\% prescribed the recommended $500 \mathrm{mg}$ single dose. Similarly, only about a third of the RMPs reported to prescribed benzathene penicillin for the treatment of syphilis, among which only $4 \%$ prescribed the correct dose of 2.4 million units IM. While a great majority (83.8\%) of RMPs suggested metronidazole for the treatment of vaginal discharge symptoms, only $4 \%$ of the RMPs used the recommended 2 gm single dose.

Role of training program: The proportion of RMPs that correctly named three out of four STDs (syphilis, gonorrhoea, trichomoniasis, and AIDS) increased from $19.2 \%$ to $36.3 \%$ following the training ( $=0.014$, Table 3). Knowledge about transmission of STI/HIV significantly increased among RMPs following the training. Only 3\% of RMPs were able to answer four out of four HIV transmission (unprotected sexual intercourse, blood transfusion, needle sharing and infected mother to child) questions correctly at baseline, while $94.9 \%$ of RMPs answered all four questions correctly following the training $(\mathrm{p}=0.001)$. While misconceptions about HIV transmission were still apparent among the trained RMPs, $67.7 \%$ of the RMPs reported at least one misconception at

Table 2. Treatment practices and referral by type of professional training at baseline assessment.

\begin{tabular}{|c|c|c|c|c|c|}
\hline \multirow{2}{*}{$\begin{array}{l}\text { Characteristics } \\
\text { N (\%) unless otherwise } \\
\text { specified }\end{array}$} & \multicolumn{3}{|c|}{ Professional training } & \multirow{2}{*}{$\begin{array}{c}\text { Total } \\
(n=225)\end{array}$} & \multirow[b]{2}{*}{$\mathrm{p}$ value } \\
\hline & $\begin{array}{l}\text { No training } \\
(\mathrm{n}=51)\end{array}$ & $\begin{array}{l}\text { Local medical } \\
\text { assistant }(\mathrm{n}=141)\end{array}$ & $\begin{array}{c}\text { Paramedical } \\
\text { training }(n=33)\end{array}$ & & \\
\hline Patients/Day (mean \pm SD) & $15.8 \pm 11.6$ & $16.7 \pm 13.6$ & $14.5 \pm 12.3$ & $16.2 \pm 12.1$ & \\
\hline $\begin{array}{l}\text { STD patients in last month } \\
\text { (Mean } \pm \text { SD) }\end{array}$ & $7.7 \pm 19.5$ & $5.2 \pm 14.6$ & $4.2 \pm 6.4$ & $5.6 \pm 15.0$ & \\
\hline \multicolumn{6}{|l|}{ How diagnose STDs in men } \\
\hline History only & $21(41.2)$ & $44(31.2)$ & $5(15.2)$ & $70(31.1)$ & \\
\hline History and physical exam & $13(25.5)$ & $54(38.3)$ & $7(21.2)$ & $74(32.9)$ & 0.004 \\
\hline History, physical and laboratory tests & $17(33.3)$ & $43(30.6)$ & $21(63.6)$ & $81(36.0)$ & \\
\hline \multicolumn{6}{|l|}{ Paper prescription to patients } \\
\hline Always & $5(9.8)$ & $11(7.8)$ & $8(24.2)$ & $24(10.7)$ & 0.016 \\
\hline Some times & $30(58.9)$ & $103(73.1)$ & $22(66.6)$ & 155 (68.9) & FET \\
\hline Never & $16(31.4)$ & $27(19.1)$ & $3(9.1)$ & $46(20.4)$ & \\
\hline \multicolumn{6}{|l|}{ Sell medicine } \\
\hline Yes & $48(94.1)$ & 135 (95.7) & $21(63.6)$ & 204 (90.7) & $<0.001$ \\
\hline No & $3(5.9)$ & $6(4.3)$ & $12(36.4)$ & $21(9.3)$ & FET \\
\hline \multicolumn{6}{|l|}{ Amount of patient fee } \\
\hline No fee & 45 (88.2) & $120(85.1)$ & $20(60.6)$ & $185(82.2)$ & \\
\hline 10 - 25 taka & $3(5.9)$ & $12(8.5)$ & $9(27.3)$ & $24(10.7)$ & 0.013 \\
\hline 26 - 50 taka & $3(5.9)$ & $9(6.4)$ & $4(12.1)$ & $16(7.1)$ & FET \\
\hline $\begin{array}{l}\text { Patients referred to next level } \\
\text { care in last month } \\
(\text { mean } \pm \text { SD) }\end{array}$ & $6.8 \pm 7.3$ & $6.48 \pm 11.0$ & $8.3 \pm 17.8$ & $6.8 \pm 11.5$ & \\
\hline
\end{tabular}

Note: FET is Fisher's exact test. 
Table 3. Changes in knowledge and practices of the rural medical practitioners who participated in training sessions $(\mathrm{n}=$ 99).

\begin{tabular}{|c|c|c|c|}
\hline Variables & Baseline (\%) $(n=99)$ & Follow up $(\%)(n=99)$ & p value ${ }^{*}$ \\
\hline \multicolumn{4}{|l|}{ Named correct STIs } \\
\hline One & 99.0 & 100 & \multirow{4}{*}{$0.014^{*}$} \\
\hline Two & 92.9 & 85.8 & \\
\hline Three & 19.2 & 36.3 & \\
\hline Four & 0 & 14.1 & \\
\hline \multicolumn{4}{|c|}{ Named correct method of STI/HIV transmission } \\
\hline One & 67.7 & 100 & \multirow{4}{*}{$<0.0001^{*}$} \\
\hline Two & 32.3 & 100 & \\
\hline Three & 12.1 & 100 & \\
\hline Four & 3.0 & 94.9 & \\
\hline \multicolumn{4}{|c|}{ Misconception about HIV transmission } \\
\hline One & 67.7 & 30.3 & \multirow{3}{*}{$<0.0001^{*}$} \\
\hline Two & 19.2 & 10.1 & \\
\hline Three & 8.1 & 6.1 & \\
\hline \multicolumn{4}{|l|}{ Ciprofloxacin for gonorrhea treatment } \\
\hline Reported as drug of choice & 51.5 & 47.5 & $0.8^{* *}$ \\
\hline Reported correct dosages & 3.0 & 5.2 & $0.7^{* *}$ \\
\hline \multicolumn{4}{|l|}{ Azithromycin for gonorrhea treatment } \\
\hline Reported as drug of choice & 10.1 & 49.5 & $<0.0001^{* *}$ \\
\hline Reported correct dosages & 2.0 & 39.4 & $<0.0001^{* *}$ \\
\hline \multicolumn{4}{|c|}{ Benzathine penicillin for syphilis treatment } \\
\hline Reported as drug of choice & 52.5 & 53.5 & $0.9^{* *}$ \\
\hline Reported correct dosages & 4.0 & 16.1 & $0.004^{* *}$ \\
\hline \multicolumn{4}{|c|}{ Metronidazole for vaginal discharge treatment } \\
\hline Reported as drug of choice & 83.8 & 88.8 & $0.36^{* *}$ \\
\hline Reported correct dosages & 4.0 & 10.1 & $0.11^{* *}$ \\
\hline $\begin{array}{l}\text { Knowledge of drug resistance } \\
\text { as a cause of antibiotic failure }\end{array}$ & 28.3 & 41.4 & $0.03^{* *}$ \\
\hline
\end{tabular}

*Wilcoxon signed-rank test; ${ }^{* *}$ McNemar test.

baseline while only $30.4 \%$ did so at follow up ( $p=0.001)$.

STI management practices: The most significant changes were observed in increased recommendation to use azithromycin for the treatment of urethral discharge (gonorrhea) syndrome. Only 10\% of RMPs recommended azithromycin at baseline with only $2 \%$ using the recommended $2 \mathrm{gm}$ single dose. At three months following the training, 49.5\% of RMPs recommended azithromycin with 39.4\% using the recommended dose (Table 3). The recommendation to benzathine penicillin for the treatment of syphilis did not change markedly, but more practitioners used the recommended single dose of 2.4 millionunits IM, from $4.0 \%$ at baseline to $16.1 \%$ at follow-up $(p=0.004)$. Use of recommended single dose $2.0 \mathrm{gm}$ metronidazole for treatment of vaginal discharge syndrome only increased from $4.0 \%$ to $10.3 \%$ at follow up ( $\mathrm{p}=0.35)$. Knowledge that drug resistance could be related to subsequent antibiotic failure due to inappropriate drug usage/dosing and/or patient compliance significantly increased from $28.3 \%$ at baseline to $41.4 \%$ at follow-up ( $\mathrm{p}=0.03)$.

Referral practices: Out of 99 RMPs attended in the training sessions, 43 of them made 326 referrals in three months time following their training. Maximum referrals were made for genital ulcer diseases (45.4\%) followed by urethral discharge (29.9\%) and vaginal cervical discharge (26.5). RMPs referred their patients to formal sector facilities more often that they reported doing so previously. Patients were mostly (59.8\%) referred to private clinics, while $17.3 \%$ of the patients were referred to specialist general practitioners.

\section{Discussion}

Rural medical practitioners are the major care providers in rural Bangladesh. Many of the surveyed RMPs had 
inadequate academic qualifications and training to practice modern medicine, yet they encounter a sizable number of patients in their daily practice, many of whom have STIs. Most of the RMPs in this study had inadequate knowledge about STI/HIV/AIDS. A similar conclusion of low RTI/STI knowledge was reported among village doctors in a study of reproductive health in rural Bangladesh [17]. Most RMPs sell medicine (90.7\%) to their clients alongside their practice as a principal income source, since most of them do not take a patient fee (82.2\%). This creates a powerful incentive to over-prescribe and over-medicate patients. A significantly higher proportion of RMPs with paramedical training are more likely to provide paper prescriptions to their patients. These trained RMPs are more likely to charge a fee, but less likely to sell medications directly and much more likely to advise laboratory tests for diagnosis of STIs. RMPs with better quality professional training are less conflicted in their interests since they are not profiting directly from sales of drugs. We did not investigate the quality and type of drugs, nor the type of laboratory investigations that were recommended.

Recommendation to use of first line antibiotics for treatment of common STIs was moderately common among this group of rural practitioners, but the inappropriate drug selection and doses were evident with respect to the national STD syndromic guidelines [19]. For example, most of the RMPs reported prescribing metronidazole for treatment of abnormal vaginal discharge (83.8\%) but only 4\% used the recommended regimen of 2 gm single dose at baseline. Many of the RMPs recommended incorrect dosages for incorrect durations as par the national syndromic management guideline, possibly for financial reasons. Such inappropriate use of antibiotics is likely to result in antibiotic resistance in countries like Bangladesh. Ciprofloxacin was considered to be highly effective for gonococcal treatment until it was found that $49 \%$ of the strains collected in a study in Bangladesh were quinolone resistant [20] [21]. Because of widely prevalent ciprofloxacin-resistant gonococcal strains in Bangladesh, azithromycin is now suggested for treatment of urethral discharge per national syndromic guidelines (a recommendation that was also emphasized in our STI/RTI orientation training sessions). However, the proportion of RMPs who recommended ciprofloxacin for urethral discharge was not found to be significantly decreased at the follow-up survey compared to the baseline survey (52\% vs. $48 \%$ ). Given RMPs central role in rural healthcare, the improvement of their knowledge and practices related to STIs management through shortterm training is crucial in enabling RMPs to use antibiotics appropriately and preventing antibiotic resistance.

Our study shows that the implementation of a two-day training program can be effective in improving the RMP's STI/HIV/AIDS knowledge and apprehension of recommended medications and dosages for the treatment of curable RTI/STI. Training was well received and improvements, albeit modest was well documented in both knowledge and practices of the RMPs. There is still considerable room for improvement in RMPs knowledge and practices; perhaps a longer training program would have a greater impact on knowledge and STI treatment practices. A systematic review on role of informal health care providers in developing countries and another study report on the management of reproductive tract infections in rural Bangladesh recommended to undertake educational interventions and capacity building exercises forum qualified village doctors, given their role as major care providers in rural areas [13] [17]. Our study reinforces the importance of this mandate in Bangladesh context.

This study was limited to apurposively selected sub-district in Bangladesh with the study outcome concentrated only to sexually transmitted infections. Generalization of study findings to other types of diseases should be done with caution. Caution is needed in the interpretation of the data because of lack of control group for comparison and the relatively short follow-up period. We did not have any immediate post training evaluation; therefore, we are not certain if changes in knowledge would have occurred anyway, without the intervention. However, that seems unlikely because the follow-up was done after three months of training and also other studies that used control group also reported similar change in knowledge as outcomes.

It is evident from the findings of this study and also through other studies [17] [22] [23] that informal providers like RMPs are capable of learning and changing their practices, even after a brief educational intervention. We call for further operations research to study how best to mobilise interactive training and multi-faceted educational interventions for RMPs to better engage them in health care for prevention and control of STIs and other health conditions by taking care of the country specific regulatory framework.

\section{Acknowledgements}

The John M. Lloyd Foundation funded the project with additional support from the Fogarty International Center 
(FIC), National Institutes of Health (2 D43 TW001035). The authors greatly acknowledge the contribution of Dr. Banibroto Nandi and Mr. Shafiqul Haider for field coordination and finally participating rural practitioners for their cooperation.

\section{Conflict of Interest}

Authors declare no conflict of interest.

\section{References}

[1] Islam, M.M., Karim, E., Mian, M.A., Kristensen, S., Chowdhury, M.R. and Vermund, S.H. (1999) An Update on the Prevalence of HIV/AIDS in Bangladesh. The Southeast Asian Journal of Tropical Medicine and Public Health, 30, 246-250.

[2] Rahman, S., Ahmed, M.U., Khuda, B. and Ahmed, S. (1999) Can Medicine-Sellers in Pharmacies Meet the Needs of STD Clients? Observations from an Urban Area of Bangladesh. Working Paper No. 159, ICDDR,B, Dhaka.

[3] Hawkes, S. and Azim, T. (2000) Health Care Systems in Transition III. Bangladesh, Part II. Bangladesh's Response to HIV-AIDS. Journal of Public Health Medicine, 22, 10-13. http://dx.doi.org/10.1093/pubmed/22.1.10

[4] Gibney, L., Saquib, N. and Metzger, J. (2003) Behavioral Risk Factors for STD/HIV Transmission in Bangladesh's Trucking Industry. Social Science \& Medicine, 56, 1411-1424. http://dx.doi.org/10.1016/S0277-9536(02)00138-7

[5] Azim, T., Khan, S.I., Haseen, F., et al. (2008) HIV and AIDS in Bangladesh. Journal of Health Population and Nutrition, 26, 311-324.

[6] Alam, N., Choudhury, M.E., Mridha, M.K., Reichenbach, L.J., Streatfield, P.K., Ahmed, A.U. and Azim, T. (2013) Factor Associated with Condom Use Negotiation among Female sex Workers in Bangladesh. International Journal of STD \& AIDS, 24, 813-821. http://dx.doi.org/10.1177/0956462413486452

[7] Rahman, M., Sultan, Z., Monira, S., Alam, A., Nessa, K., Islam, S., Nahar, S., Waris, S.A., Alam Khan, S., Bogaerts, J., Islam, N. and Albert, J. (2002) Antimicrobial Susceptibility of Neisseria gonorrhoeae Isolated in Bangladesh (1997 to 1999): Rapid Shift to Fluoroquinolone Resistance. Journal of Clinical Microbiology, 40, 2037-2040. http://dx.doi.org/10.1128/JCM.40.6.2037-2040.2002

[8] Ministry of Health and Family Welfare and CIET Canada (1999) Baseline Service Delivery Survey: Health and Population Sector Programme 1998-2003, Bangladesh. 105 p.

[9] Wasserheit, J.N. (1992) Epidemiological Synergy. Interrelationships between Human Immunodeficiency Virus Infection and Other Sexually Transmitted Diseases. Sexually Transmitted Diseases, 19, 61-77. http://dx.doi.org/10.1097/00007435-199219020-00001

[10] Mayaud, P. and McCormick, D. (2001) Interventions against Sexually Transmitted Infections (STI) to Prevent HIV Infection. British Medical Bulletin, 58, 129-153. http://dx.doi.org/10.1093/bmb/58.1.129

[11] Grosskurth, H., Mosha, F., Todd, J., Mwijarubi, E., Klokke, A., Senkoro, K., Mayaud, P., Changalucha, J., Nicoll, A., kaGina, G., et al. (1995) Impact of Improved Treatment of Sexually Transmitted Diseases on HIV Infection in Rural Tanzania: Randomised Controlled Trial. The Lancet, 346, 530-536. http://dx.doi.org/10.1016/S0140-6736(95)91380-7

[12] Grosskurth, H., Gray, R., Hayes, R., Mabey, D. and Wawer, M. (2000) Control of Sexually Transmitted Diseases for HIV-1 Prevention: Understanding the Implications of the Mwanza and Rakai Trials. The Lancet, 355, 1981-1987. http://dx.doi.org/10.1016/S0140-6736(00)02336-9

[13] Sudhinaraset, M., Ingram, M., Lofthouse, H.K. and Montagu, D. (2013) What Is the Role of Informal Healthcare Providers in Developing Countries? A Systematic Review. PLOS ONE, 8, e54978. http://dx.doi.org/10.1371/journal.pone.0054978

[14] Ahmed, S.M., Hossain, M.A., Rajachowdhury, A.M. and Bhuiya, A.U. (2011) The Health Workforce Crisis in Bangladesh: Shortage, Inappropriate Skill-Mix and Inequitable Distribution. Human Resources for Health, 9, 3. http://dx.doi.org/10.1186/1478-4491-9-3

[15] Amin, R., Chowdhury, S.A., Kamal, G.M. and Chowdhury, J. (1989) Community Health Services and Health Care Utilization in Rural Bangladesh. Social Science \& Medicine, 29, 1343-1349. http://dx.doi.org/10.1016/0277-9536(89)90234-7

[16] Ronsmans, C., Bennish, M.L., Chakraborty, J. and Fauveau, V. (1991) Current Practices for Treatment of Dysentery in Rural Bangladesh. Reviews of Infectious Diseases, 13, S351-S356. http://dx.doi.org/10.1093/clinids/13.Supplement_4.S351

[17] Ahmed, M.U., Mirza, T., Khanum, P., Khan, M.A., Ahmed, S. and Khan, M.H. (1999) Management of Reproductive 
Tract Infections in Rural Bangladesh. International Journal of STD \& AIDS, 10, 263-267. http://dx.doi.org/10.1258/0956462991913916

[18] SPSS Inc. (2005) SPSS 17.0 for Windows (Computer Program). Version 17.0, SPSS Inc., Chicago.

[19] National Integrated Population and Health Programme (NIPHP) (1999) Ministry of Health and Family Welfare. Technical Standard and Service Delivery Protocol for Management of RTI/STD.

[20] Rahman, M., Sultan, Z., Monira, S., Alam, A., Nessa, K., Islam, S., Nahar, S., Shama-A-Waris, Khan, S.A., Bogaerts, J., Islam, N. and Albert, J. (2002) Antimicrobial Susceptibility of Neisseria gonorrhoeae Isolated in Bangladesh (1997 to 1999): Rapid Shift to Fluoroquinolone Resistance. Journal of Clinical Microbiology, 40, 2037-2040. http://dx.doi.org/10.1128/JCM.40.6.2037-2040.2002

[21] World Health Organization (2001) Intervention and Strategies to Improve the Use of Antimicrobials in Developing Countries. Drug Management Programme. WHO Document WHO/CDS/CSR/DRS/2001.9, WHO, Geneva.

[22] Lan, P., Phuc, H., Hoa, N., Chuc, N. and Lundborg, C. (2014) Improved Knowledge and Reported Practice Regarding Sexually Transmitted Infections among Healthcare Providers in Rural Vietnam: A Cluster Randomised Controlled Educational Intervention. BMC Infectious Diseases, 14, 646. http://dx.doi.org/10.1186/s12879-014-0646-5

[23] Hamid Salim, M.A., Uplekar, M., Daru, P., Aung, M., Declercq, E. and Lönnroth, K. (2006) Turning Liabilities into Resources: Informal Village Doctors and Tuberculosis Control in Bangladesh. Bulletin of the World Health Organization, 84, 479-484. http://dx.doi.org/10.2471/BLT.05.023929 